Case Report

\title{
Beyond the Transition: Long-Term Population Trends in a Disadvantaged Region of Southern Europe, 1861-2017
}

\author{
Rosanna Salvia ${ }^{1}\left(\right.$, Luca Salvati ${ }^{2, *}$ and Giovanni Quaranta ${ }^{1}(\mathbb{C}$ \\ 1 Mathematics, Computer Science and Economics Department, University of Basilicata, I-85100 Potenza, Italy; \\ rosanna.salvia@unibas.it (R.S.); giovanni.quaranta@unibas.it (G.Q.) \\ 2 Department of Economics and Law, University of Macerata, I-62100 Macerata, Italy \\ * Correspondence: luca.salvati@unimc.it
}

check for updates

Citation: Salvia, R.; Salvati, L.; Quaranta, G. Beyond the Transition: Long-Term Population Trends in a Disadvantaged Region of Southern Europe, 1861-2017. Sustainability 2021, 13, 6636. https://doi.org/ $10.3390 /$ su13126636

Academic Editor: Brantley Liddle

Received: 10 May 2021

Accepted: 9 June 2021

Published: 10 June 2021

Publisher's Note: MDPI stays neutral with regard to jurisdictional claims in published maps and institutional affiliations.

Copyright: (c) 2021 by the authors. Licensee MDPI, Basel, Switzerland. This article is an open access article distributed under the terms and conditions of the Creative Commons Attribution (CC BY) license (https:/ / creativecommons.org/licenses/by/ $4.0 /)$.

\begin{abstract}
The long-term impact of demographic transitions on the spatial distribution of human settlements was occasionally evaluated in Europe. Assuming the distinctive role of urban-rural divides, our study investigates local-scale population trends (1861-2017) in Southern Italy, a disadvantaged region of Mediterranean Europe, as a result of long-term socioeconomic transformations. A quantitative analysis of municipal-scale population data based on descriptive and exploratory multivariate statistics, mapping, inferential approaches, and regression models identified four time intervals with distinctive demographic dynamics: (i) a spatially homogeneous population growth between 1861 and 1911, (ii) a moderate population increase rebalancing a traditional divide in coastal and internal areas (1911-1951), (iii) accelerated population growth enlarging spatial divides in urban and rural districts (1951-1981), and (iv) population stability (or slight decline) leading to heterogeneous demographic patterns since the early 1980s. The first three stages reflect a prolonged transition from high fertility and mortality to high fertility and low mortality, with accelerated population growth typical of the latest stage of the first demographic transition. Outcomes of time interval (iv) reflect the early stages of the second demographic transition, with lowest-low fertility and rising life expectancy. While the first transition reflected spatially homogeneous population trends along a considerable time spam, the second transition has been associated with heterogeneous (leapfrog) demographic patterns as a result of socially mixed (and spatially) fragmented dynamics of growth and change.
\end{abstract}

Keywords: population growth; multivariate analysis; urban-rural divide; southern Italy

\section{Introduction}

Demographic transitions have leveraged (and are in turn influenced by) socioeconomic changes impacting settlement dynamics and stimulating a complete spatial restructuring of countries and regions, especially in advanced economies [1-4]. Unprecedented rates of natural population increase, large migratory flows from rural to urban areas, and intense transformation of previously rural locations to metropolitan status, are considered immediate sources of population growth [5-7]. Urbanization and demographic transitions reveal how population concentration affects fertility and mortality rates via agglomeration economies and congestion diseconomies [8]. These dynamics determined sequential rises and declines in population growth rates reflected in an inverted U-shaped pattern over time, typical of a demographic process known as the first transition [9]. The 'demographic transition' theory was proposed to explain the historical shift from high birth rates and high infant death rates in developing societies, to low birth rates and low death rates in advanced economies, delineating four stages (numbered from 1 to 4 in Figure 1) with distinctive demographic attributes moving from the first to the last scenario mentioned above. While occurring (more or less synchronically) in almost all industrialized countries, specific social, political, and economic factors affecting particular populations have influenced this demographic shift, resulting in strictly homogeneous dynamics only in some cases $[10,11]$. 
The existence of a 'demographic transition' is accepted in the social sciences because of the well-established historical correlation linking fertility decline to socioeconomic development. Additionally, at the end of the historical decline in both mortality and fertility, characteristic of the last stage of the first transition, new socio-demographic phenomena were observed in advanced economies of the Western World, representing a completely different shift toward new population patterns [12-14]. In this context, the so-called 'second demographic transition' attempted to explain features such as the baby bust, the systematic postponement of marriage and parenthood, sub-replacement fertility, the rise of alternative forms of partnerships, and parenthood outside marriage [15]. Theory underlying this recent transition integrates an economic component grounded on the assumption of rational choices and a cultural component relying on Maslow's theory of shifting needs, making the spatial outcomes of the second transition spatially mixed, socially fragmented, and largely unpredictable [16].

As far as the individual behaviors, the two demographic transitions differ in marriage choices, family creation, propensity to childbearing, and spatial mobility [17-19]. The outcomes of these transitions have long been explored over time, highlighting differences in fertility and mortality patterns and, subsequently, in the individual choices that lead to marriage postponement, cohabitation, formation of non-traditional families, childbearing postponement, and increased mobility for study, work, or leisure [20-22]. At the same time, these outcomes have had important implications for population dynamics at both regional and local scale [23]. However, the spatial outcomes of the two demographic transitions, in both advanced economies and emerging countries, have generally been less studied. In this perspective, integration of spatio-temporal dimensions of the first and second transitions in a refined analysis of population growth (and decline) is increasingly required. As a matter of fact, a comprehensive analysis of how short-term demographic dynamics and long-term transitions impact population distribution across regions, may provide an enhanced understanding of the spatial mechanisms of urban growth, reconnecting aggregated patterns and individual behaviors into a unified socioeconomic and territorial interpretation [24-26].

In Europe, the spatial outcomes of demographic transitions were less intensively studied than the respective changes in population structures and dynamics over time [27]. However, population changes underlying the first demographic transition were at the base of the inherent transformation of local districts, exalting urban-rural divides and redesigning metropolitan hierarchies across the continent [12]. Compared with Western Europe, a late transition was observed in the Northern Mediterranean basin, a region with traditional human settlements characterized by reduced accessibility and partial infrastructures, disadvantaged economic conditions, and secularized societies reflected in medium-high fertility, natural population growth, and emigration, observed over the last century [28]. Concentration of population along the sea coast and depopulation of inland rural areas were key demographic trends in Southern Europe [29-31].

Industrial development, infrastructural growth, and tourism expansion contributed to increase disparities in urban and rural districts, alimenting a prolonged transition toward a dualistic model with distinctive demographic attributes [23]. This growth model-in Italy as in Spain, in Portugal as in Greece-was at the base of fragmented metropolitan systems led by a restricted number of large urban regions [32], and a poorly interconnected network of medium-sized and small towns [33]. At the same time, the economic backwardness of rural districts in Mediterranean Europe was a consequence of late industrialization, poor accessibility, infrastructural deficiencies, and the structural distance from the leading regions in Europe [34].

While micro-scale implications of demographic transitions in advanced economies (e.g., changes in individual behaviors) have been analyzed over time, spatial outcomes as far as long-term population trends are concerned have been investigated more occasionally in Mediterranean Europe. Understanding distinctive settlement dynamics and population growth along demographic transitions requires identification of socioeconomic forces 
and territorial factors assuring system stability or promoting change. Assuming different population dynamics along urban-rural and coastal-inland gradients, the present study investigates long-term population trends (1861-2017) in Southern Italy, a disadvantaged region of Mediterranean Europe, as a consequence of sequential demographic transitions. We hypothesized that demographic transitions in the study area have affected the spatial distribution of resident population as a joint result of variations in fertility, mortality, and spatial (internal and international) mobility.

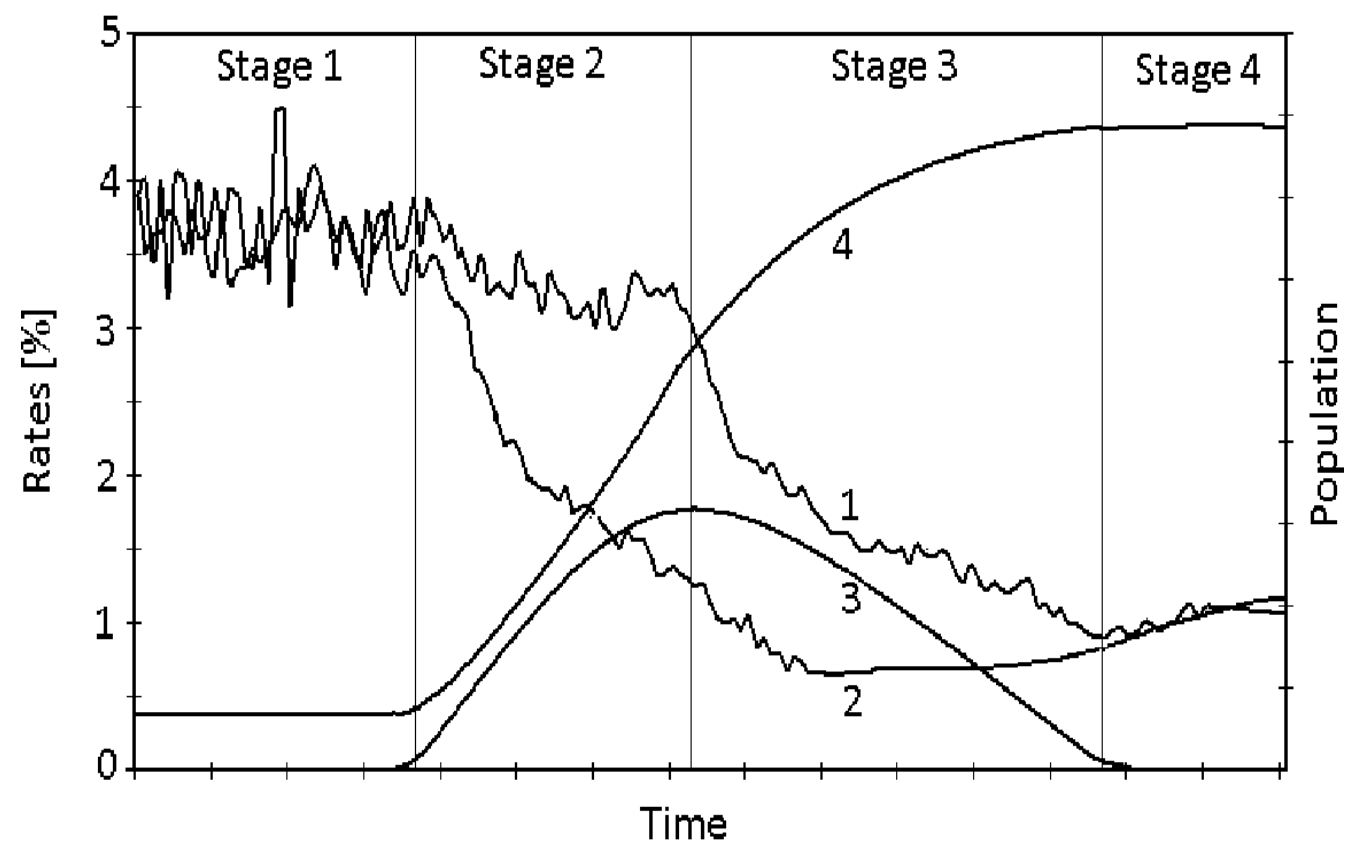

Figure 1. A summary description of the main stages of the first demographic transition in advanced economies based on four attributes (from 1 to 4 : birth rate, death rate, rate of natural increase, and total population).

More specifically, we assumed that the spatial distribution of population in Southern Europe has mainly reflected a typical urban-rural divide with accelerated growth of metropolitan areas typical of the late phase of the first demographic transition $[27,35,36]$. The second transition has represented a much more heterogeneous regime progressively decoupled from traditional geographical gradients [37-39]. A comprehensive analysis of population growth rates at the municipal scale from time series (1861-2017) census data was developed with the aim at testing this hypothesis, in turn controlling for population density, past demographic dynamics, and basic territorial characteristics. The role of specific geographical gradients shaping population dynamics was finally investigated adopting a mixed statistical framework that integrates descriptive statistics, inferential techniques, multivariate analysis, and spatial correlation.

\section{Methodology}

\subsection{Study Area}

Southern Italy is a polarized region representative of mostly disadvantaged economic districts in Mediterranean Europe [30,40]. The study area includes 8 out of 20 Italian administrative regions (Abruzzo, Molise, Campania, Apulia, Basilicata, Calabria, Sicily, and Sardinia) with a surface area extending $143,196 \mathrm{~km}^{2}$ and administered by less than three thousand municipalities (Figure 2). 

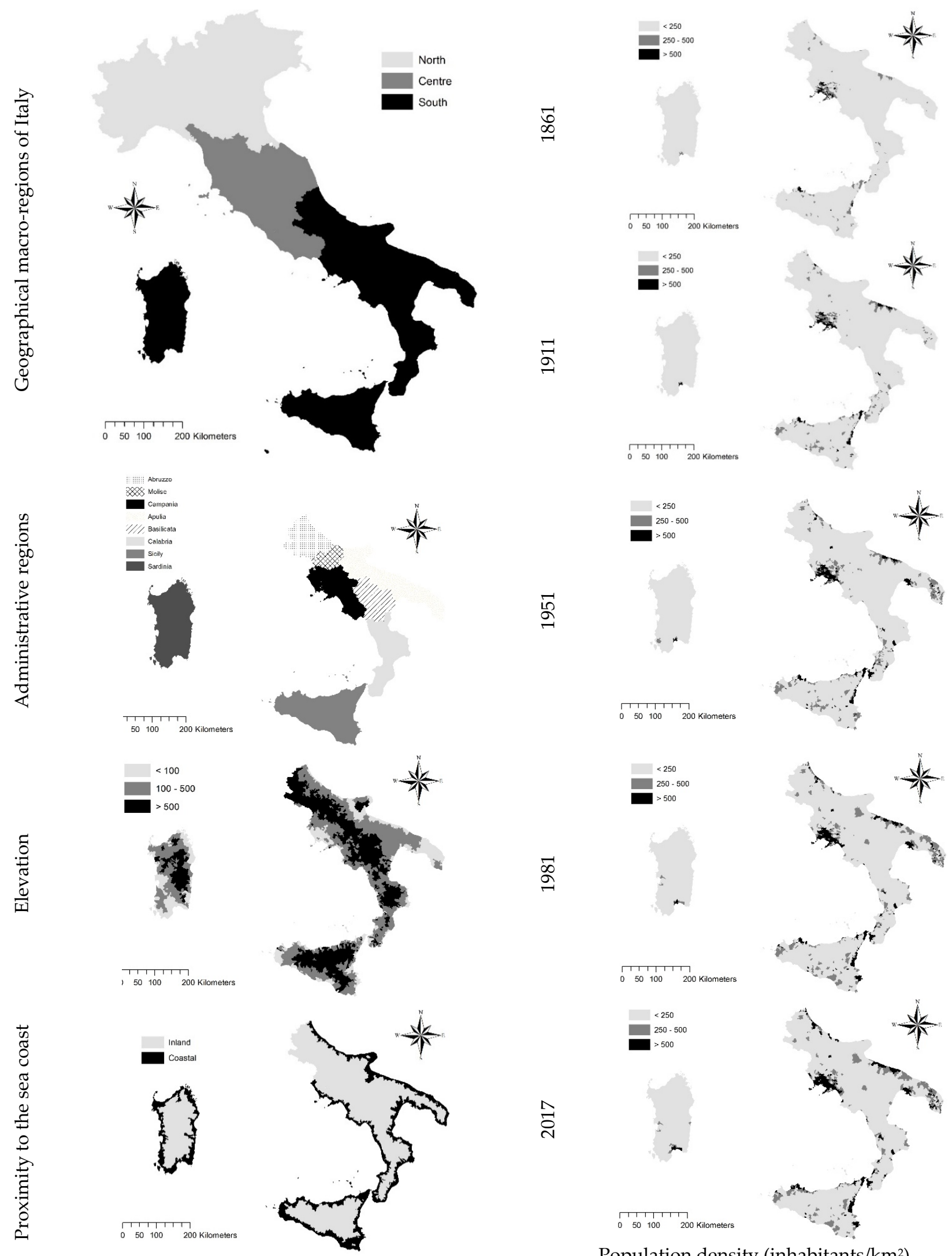

Population density (inhabitants $/ \mathrm{km}^{2}$ )

Figure 2. Maps illustrating selected territorial characteristics of the study area (left column) and population density at selected years, 1861-2017 (right column). 
The European Development framework classified Southern Italy as a Target 2 region (with an average per-capita income significantly lower than the rest of Italy) and, according to such classification, the eight administrative regions mentioned above were eligible to receive development funds and subsidies from structural funds (e.g., the European Regional Development Program, FESR; and the European Social Program, FSE) and rural development policies. Southern Italian land is mainly steep and characterized by a complex environmental configuration with traditional rural landscapes still dominating the largest part of the area. The Apennine mountain district extends a large part of the region, leaving few space to flat (or gently steep) land, with negative implications for infrastructural development. Apart from some port facilities, structural lacks in a modern system of railways and highways, and a spatially fragmented network of airports-with few international airports, such as Naples-limited the accessibility from the rest of the country and from the neighboring European countries. The spatial distribution of resident population was (and still is) traditionally polarized in hyper-dense urban areas (Naples, Bari, Palermo, Catania, Cagliari) and marginal rural districts (the Apennine region, Central Sardinia, and inland Sicily), thus making Southern Italy a typical example of economically disadvantaged regions in Mediterranean Europe, with demographic dynamics similar to what was observed in rural Greece, inland Spain, and northern Portugal. A brief overview of selected indicators profiling Southern Italy in comparison with neighboring socioeconomic contexts in Central and Northern Italy was provided in Table 1.

Table 1. Selected indicators profiling the socioeconomic context of Italian macro-regions based on official statistics (source: Istat) referring to the last available year (2018 or 2019).

\begin{tabular}{lccc}
\hline Variable & North & Centre & South \\
\hline Per-capita income (Euros) & 34,900 & 30,700 & 18,900 \\
Total employed (\%) & 71 & 68 & 47 \\
Unemployment rate (\%) & 6 & 7 & 19 \\
Average number of components per family & 2.3 & 2.3 & 2.6 \\
Immigrants (\%) & 13.1 & 7.9 & 4.4 \\
Death rate per 1000 inhabitants & 10.9 & 10.7 & 9.9 \\
Total fertility rate & 1.34 & 1.23 & 1.26 \\
Civil weddings (\%) & 64.0 & 48.5 & 30.4 \\
\hline
\end{tabular}

\subsection{Data and Variables}

Estimates of resident population were made available at the municipal spatial scale approximately every 10 years over a sufficiently long time interval (1861-2017). The original data, aggregated at the municipal scale from the individual records of National Population Censuses and standardized for small changes in municipal boundaries over time, were derived from Istat [41]. The most recent data (2017) were derived from the national population register (held by the Italian Institute of Statistics, Istat), whose results were previously aligned with the last population census (2011). The annual rate of population growth (\%) was the target variable of this study, being calculated at each municipality over 15 time intervals of equal length (apart from three exceptions, according to different census timing or unavailability of official data sources, e.g., during World War II): 1861-1871, 1871-1881, 1881-1901, 1901-1911, 1911-1921, 1921-1931, 1931-1936, 1936-1951, 1951-1961, 1961-1971, 1971-1981, 1981-1991, 1991-2001, 2001-2011, and 2011-2017. Population density (hereafter 'density', inhabitants $/ \mathrm{km}^{2}$ ) was also calculated at 16 time points between 1861 and 2017 at the same spatial scale.

Additional variables were considered with the aim to profile the local context in each municipality of Southern Italy [42]: (i) average municipal elevation (hereafter 'Elevation', $\mathrm{m}$ ), (ii) proximity to the sea coastline ('Sea', a dummy variable assigning a value of 1 to coastal municipalities and 0 to internal municipalities), (iii-vii) five dummies capturing distinctive population trends in the largest regions of Southern Italy ('Campania', 'Apulia', 'Calabria', 'Sicily', and 'Sardinia'), and (viii) a variable controlling for the possible 
influence of municipal size on population dynamics ('Area', $\mathrm{km}^{2}$ ). Use of variables such as population density, mean elevation, and proximity to the sea coastline, contributed to clarify the role of specific geographical gradients, considered the most important factors at the base of spatial population divides in Southern Italy and, more generally, in Mediterranean Europe $[36,43,44]$. Municipal size was regarded as a control variable checking if the administrative dimension of local authorities (basically, land area) may have affected long-term population dynamics. We assumed a neutral (or slight) effect of municipal size on demographic dynamics in Southern Italy.

\subsection{Statistical Analysis}

A preliminary analysis of changes over time in population density and annual rates of population growth (\%) was carried out calculating descriptive statistics (averages or percentages) by year (or time interval) and elevation belt (lowland $<100 \mathrm{~m} ; 100 \mathrm{~m}<$ upland $<500 \mathrm{~m}$; mountain $>500 \mathrm{~m}$ ). A multivariate strategy was subsequently developed integrating multivariate exploratory techniques (Principal Component Analysis and nonhierarchical clustering) with an inferential analysis (stepwise multiple regression) aimed at characterizing the intrinsic relationship between demographic transitions, population growth, and the local context. Statistical techniques adopted in this study were individually illustrated in the following paragraphs.

\subsubsection{Principal Component Analysis}

To identify the most important territorial factors underlying demographic transitions in Southern Italy, a Principal Component Analysis (PCA) was performed on a data matrix composed of the annual rate of population growth (\%) calculated for 15 time intervals between 1861-1871 and 2011-2017 (see Section 2.2) at each municipality of the study area. The analysis was based on spectral decomposition of the correlation matrix, and the number of significant components was chosen by inspecting the scree-plot and considering eigenvalues higher than 1 [45]. Component loadings and scores were used to delineate spatio-temporal relationships between variables (time intervals with specific rates of population growth) and cases (municipalities), obtaining a comprehensive classification of spatial population trends in Southern Italy. Component scores were correlated pair-wise with the contextual variables presented in Section 2.2 using non-parametric Spearman co-graduation coefficients testing for significance at $p<0.05$ after Bonferroni's correction for multiple comparisons. A non-parametric technique was preferred to more standard approaches (e.g., the product-moment Pearson coefficient) with the final objective to identify both linear and non-linear correlations among variables. In the case of non-parametric correlations, testing at $p<0.05$ after Bonferroni corrections for multiple comparisons means that the formal inference level is automatically reduced to a probability value close to $p<0.001$, discriminating intense relationships from weaker (possibly, non-causative) linkages between variables.

\subsubsection{Non-Hierarchical Clustering}

To classify municipalities into groups with homogeneous long-term population dynamics, a non-hierarchical clustering was run on the same data matrix (annual rates of population growth) using the standard $k$-means computation strategy. Following the parsimony criterion, the procedure was run for a set of possible solutions (i.e., cluster numbers) ranging from 2 to 10. A higher number of partitions was considered inappropriate to depict the demographic characteristics of the study area. Standard diagnostics such as the pseudo $F$ statistic and the Cubic Clustering Criterion were considered to identify the best cluster partition, i.e., the number of suitable clusters that allows for the most significant discrimination among municipalities. Each cluster was profiled considering descriptive statistics (e.g., mean values) of the territorial variables illustrated above (Section 2.2). 


\subsubsection{Stepwise Multiple Regression}

To assess the multivariate relationship between the annual rate of population growth (taken as the dependent variable) and the local context (nine predictors illustrated in Section 2.2 that include population density), a multiple regression approach was run at the spatial scale of municipalities, separately for each time interval between 1861-1871 and 2011-2017. Contextual indicators were included in each model based on a forward stepwise strategy under a significant Fisher-Snedecor F test at $p<0.01$ [45]. Results include slope coefficient estimates and the associated significance level (testing for the null-hypothesis of non-significant regression coefficients) based on Student $t$ statistics at $p<0.05$. The goodness-of-fit of each regression model was measured using adjusted $\mathrm{R}^{2}$ and tested for significance (against the null hypothesis of non-significant models) through a Fisher-Snedecor F test with $p<0.001$. All variables were standardized prior to analysis [33].

In this study, stepwise regression was regarded as an exploratory approach, with no specific assumptions on the goodness-of-fit of each tested model. While high goodness-offit indexes (i.e., adjusted- $R^{2}$ ) and significant regression coefficients (i.e., slope coefficients) were expected when a formal theory is verified, our exploratory perspective allows identification of the latent, multivariate relationship among dependent variables and predictors, focusing on statistical significance. In other words, we assume a variable goodness-of-fit and heterogeneous regression coefficients over time. Goodness-of-fit of models run separately for each time interval was considered a proxy of dependence (or independence) of population growth processes from the background territorial context. The Durbin Watson (DW) statistic was run separately for each model as a standard test for autocorrelation in the residuals of stepwise regressions. Assuming values that range between 0 and 4 , values around 2 mean no autocorrelation detected in the sample. Starting from the 'exploratory' perspective mentioned above, the unexplained proportion of variance in our regression models is an important finding, opening new perspectives of investigations typical of non-confirmatory approaches grounded on ecological theory.

\subsubsection{Analysis of the Spatial Distribution of Population}

To identify the overall impact of demographic transitions on the spatial distribution of population in Southern Italy, metrics of central tendency, dispersion, and asymmetry were calculated on municipal-scale population density at each time point between 1861 and 2017. Metrics assessing central tendency include (i) the ratio of median to (arithmetic) mean density, (ii) the ratio of median to grand total density (Southern Italy), and (iii) the ratio of (harmonic) mean to grand total density. Metrics assessing dispersion include (iv) minimum and (v) maximum density, (vi) the ratio of absolute range (Max-Min) to arithmetic mean density, (vii) coefficient of variation, (viii) 25th-percentile and (ix) 75thpercentile of population density, as well as $(x)$ the ratio of the interquartile score (75th-25th percentile) to the absolute range of population density (Max-Min). Finally, (xi) kurtosis and (xii) skewness were used to assess asymmetry in the statistical distribution of population density over time. To assess the latent relationship between demographic transitions and the spatial distribution of population over time, a Principal Component Analysis was run on a data matrix containing the 12 indicators illustrated above and calculated at 16 time points.

\section{Results}

3.1. Long-Term Population Dynamics in Southern Italy, 1861-2017

On average, population density in Southern Italy grew from 78 inhabitants $/ \mathrm{km}^{2}$ in 1861 to 168 inhabitants $/ \mathrm{km}^{2}$ in 2017 (Table 2). 
Table 2. Selected characteristics and spatial distribution of Southern Italy population (\% share in total figure) by elevation belt and year.

\begin{tabular}{lccccc}
\hline Variable & $\mathbf{1 8 6 1}$ & $\mathbf{1 9 1 1}$ & $\mathbf{1 9 5 1}$ & $\mathbf{1 9 8 1}$ & $\mathbf{2 0 1 7}$ \\
\hline Population density & 78 & 110 & 144 & 163 & 168 \\
Population growth (\%) & - & 0.80 & 0.77 & 0.45 & 0.09 \\
Percent share in total population by district & & & & & \\
Lowland & 22.0 & 26.2 & 31.0 & 37.8 & 39.9 \\
Coastal upland & 25.6 & 27.0 & 27.8 & 29.8 & 30.4 \\
Internal upland & 28.4 & 26.8 & 24.2 & 19.8 & 18.8 \\
Coastal mountain & 4.2 & 3.9 & 3.7 & 3.1 & 2.8 \\
Internal mountain & 19.8 & 16.1 & 13.3 & 9.4 & 8.1 \\
\hline
\end{tabular}

Population increased in lowlands and coastal uplands and declined in internal uplands and mountain districts. The percent share of resident population in lowland districts in total population was 22\% in 1861, doubling in 2017 (40\%). Coastal uplands maintained a relatively high share of resident population, increasing from $26 \%$ in 1861 to 30\% in 2017. Population in mountainous districts close to the sea was relatively stable to $3-4 \%$ along the entire study period. The largest decreases were observed in internal districts, both uplands (from $28 \%$ to $19 \%$ ) and mountains (from $20 \%$ to $8 \%$ ). Spatially imbalanced population growth-especially during the period 1951-1981—consolidated the demographic divide between coastal and inland areas. High fertility, a progressive reduction of mortality and, more recently, international migration were the main factors boosting population growth in Southern Italy. Emigration rates were particularly high up to the mid-1930s and decreased between the late 1940s and the early 1970s (Figure 3). At the same time, internal migration to Northern Italy was particularly intense between the late 1940s and the mid-1970s, leading to a slightly negative internal balance.

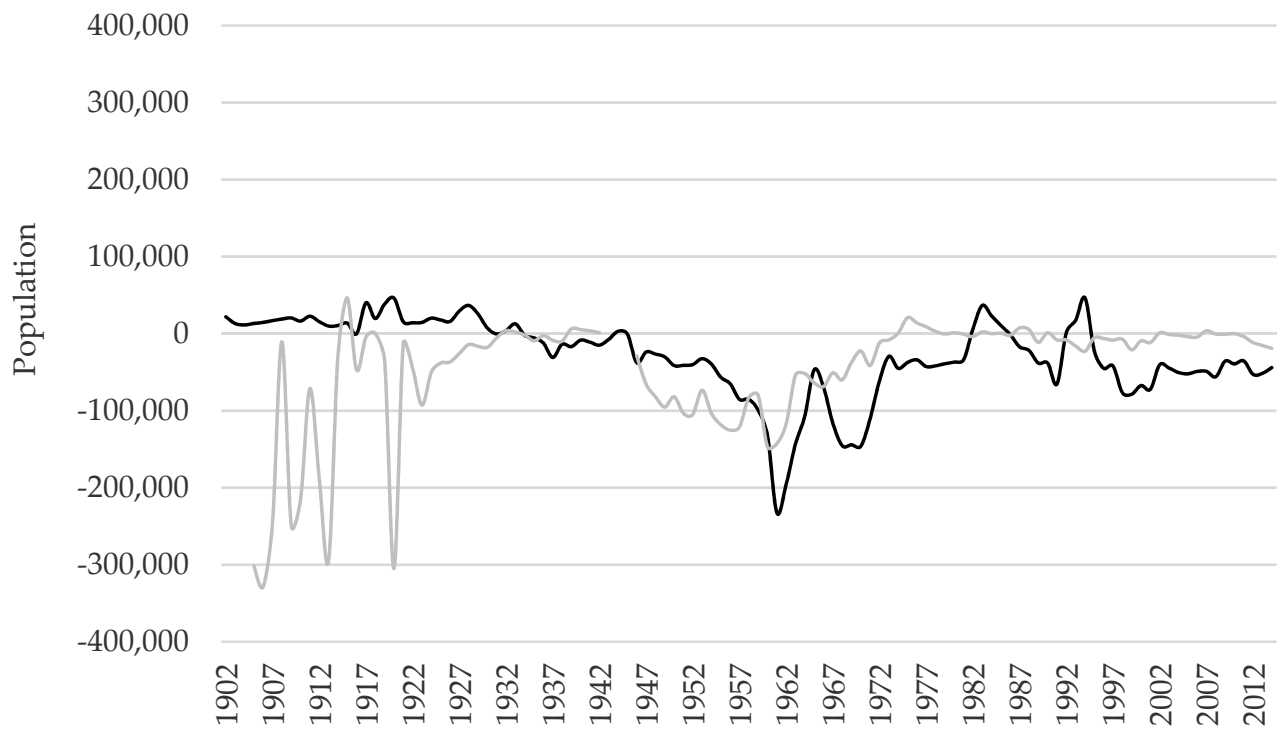

(a)

Figure 3. Cont. 


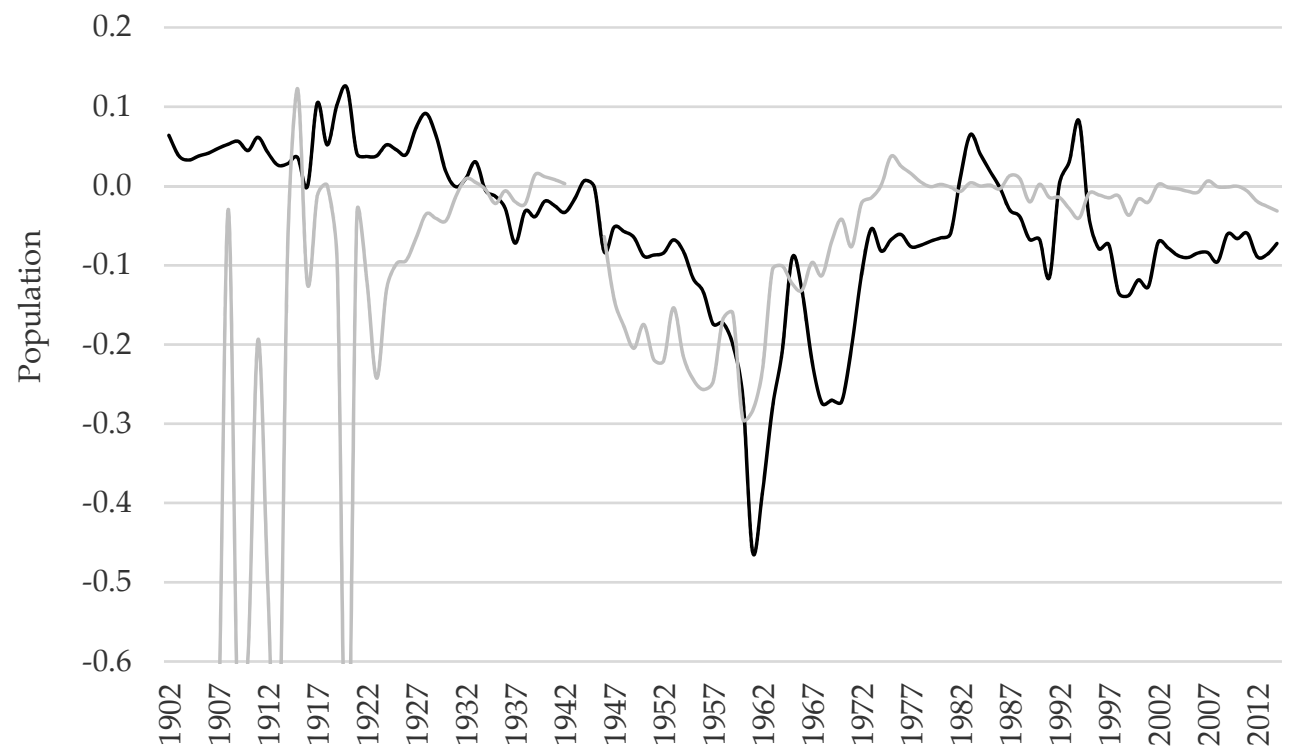

(b)

Figure 3. Migration balance in Southern Italy (black: internal movements; grey: movements from/to abroad); (a) absolute balance; $(\mathbf{b})$ relative balance (movements in total resident population).

Analysis of changes over time in the spatial distribution of population growth rates in Southern Italy (Figure 4) identified major demographic expansions in correspondence with the following time periods: 1861-1871, 1931-1936, and 1936-1951. Spatially mixed rates of growth were observed in 1871-1881 (with a moderate decline along the Apennine mountains), 1881-1901 (with a marked decline in the internal districts of Basilicata), and 1901-1911 (with a generalized decline in mountainous districts of Abruzzo, Basilicata, and Sicily). Even more polarized rates of growth were recorded since the early 1950s, distinguishing lowlands with expanding population from inland districts with declining population. A particularly fragmented distribution of growth rates was recorded in the last two time intervals, since 2001. The population increase between 1951 and 1991 was particularly intense in metropolitan regions (Figure 5). By contrast, similar rates of growth in urban and rural municipalities were observed between 1861 and 1911. Since the early 1990s, population increased more rapidly in rural municipalities than in urban areas.

\subsection{A Multivariate Analysis of Local-Scale Population Growth}

The empirical results of a Principal Component Analysis run on the annual rates of population growth by time interval and municipality in Southern Italy were illustrated in Table 3 and Figure 6. 

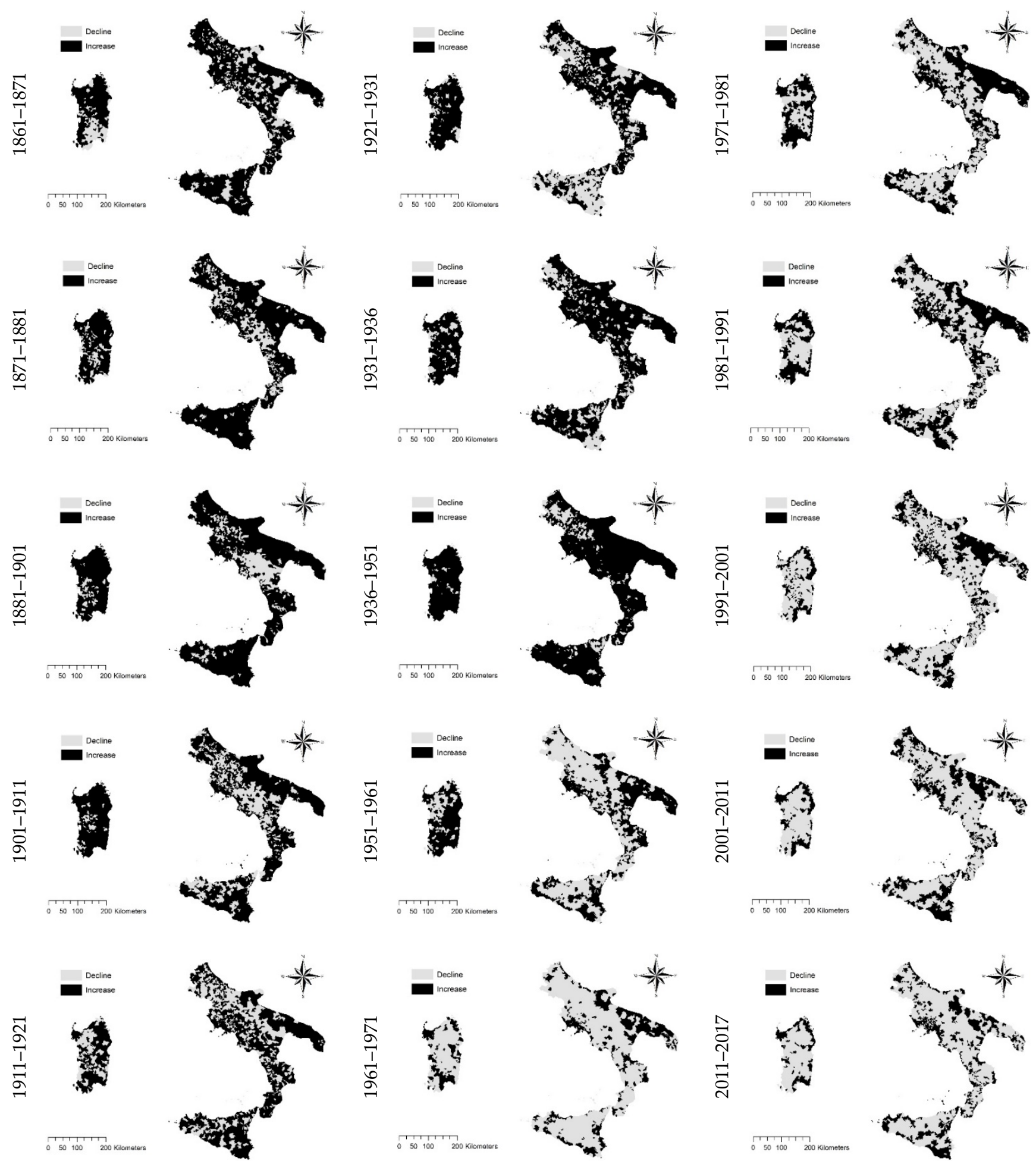

Figure 4. Spatial distribution of the annual population growth rate (\%) in the municipalities of Southern Italy by time interval. 


\section{5}

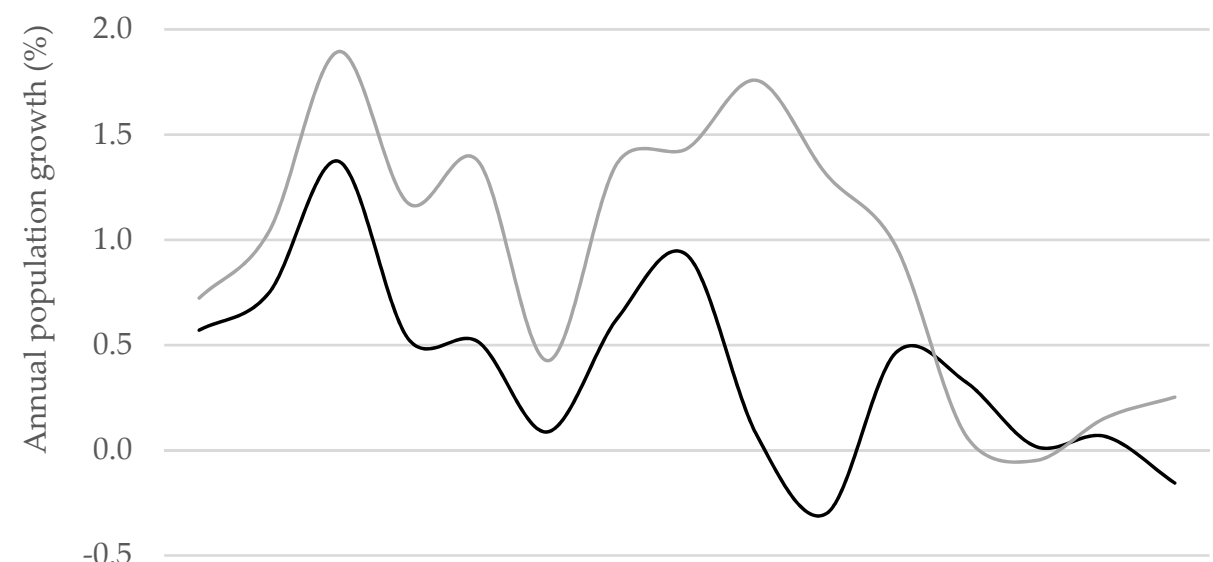

187118811901191119211931193619511961197119811991200120112017

Figure 5. Annual population growth rate (\%) in Southern Italy by year and municipal type (grey = urban; black = rural).

Table 3. Principal Component (PC) loadings of the annual rate of population growth by time interval (significant coefficients between variables and loadings were shown).

\begin{tabular}{lcccc}
\hline Time Interval & PC 1 & PC 2 & PC 3 & PC 4 \\
\hline $1861-1871$ & & & 0.40 & \\
$1871-1881$ & & 0.42 & 0.61 & \\
$1881-1901$ & & & & \\
$1901-1911$ & & & & \\
$1911-1921$ & & & & \\
$1921-1931$ & & & & \\
$1931-1936$ & 0.41 & & & \\
$1936-1951$ & 0.61 & & & \\
$1951-1961$ & 0.75 & & & \\
$1961-1971$ & 0.81 & & & \\
$1971-1981$ & 0.76 & & & \\
$1981-1991$ & 0.51 & -0.58 & & \\
$1991-2001$ & 0.64 & & & \\
$2001-2011$ & 0.60 & 9.9 & & \\
2011-2017 & 25.5 & & & \\
\% explained variance & & & & \\
\hline
\end{tabular}

Four components were selected, explaining 51\% of the total matrix variance (Table 2). These components identify distinct spatial processes with specific demographic characteristics and peculiar growth rates. Component 1 assigned positive loadings to all time intervals since 1936, with the highest value observed for the decade 1971-1981. The spatial distribution of positive scores on Component 1 identifies areas with the highest population density in Apulia, Campania, coastal Sicily, and Sardinia and, more generally, in flat, accessible districts around the largest cities (Naples, Bari, Palermo, Catania, Cagliari). Conversely, negative scores characterized inland areas along Apennines and in upland Sardinia and Sicily. These areas had the lowest population density in Southern Italy (Figure 6). 


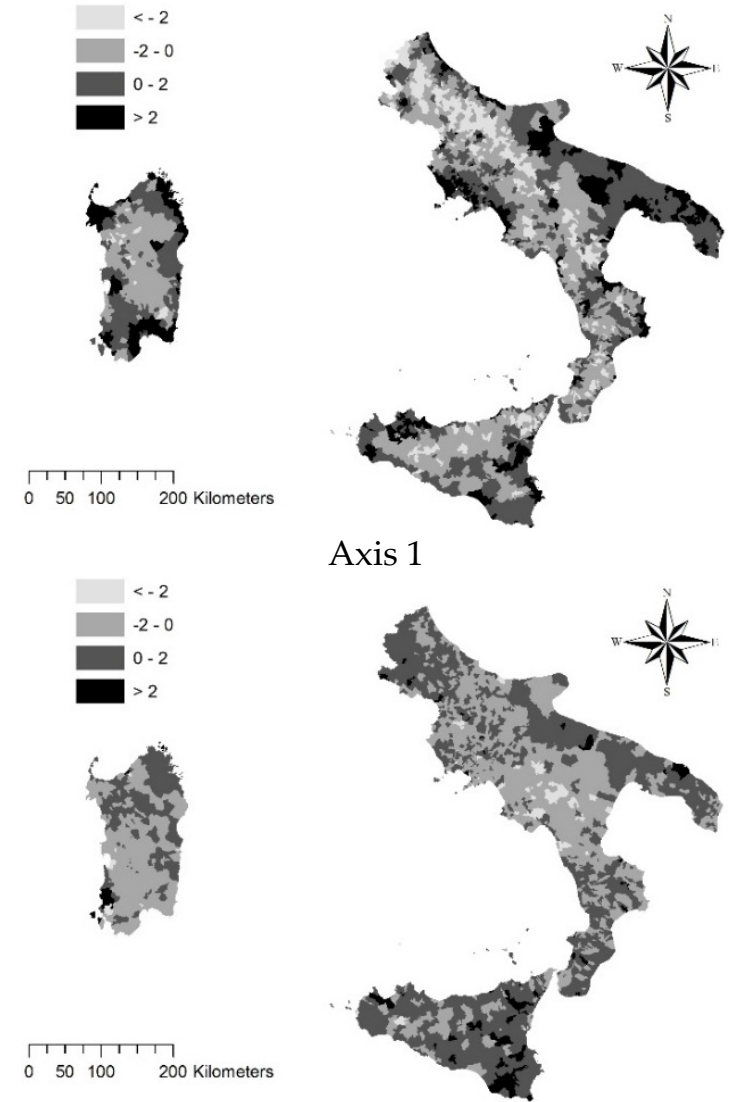

Axis 3

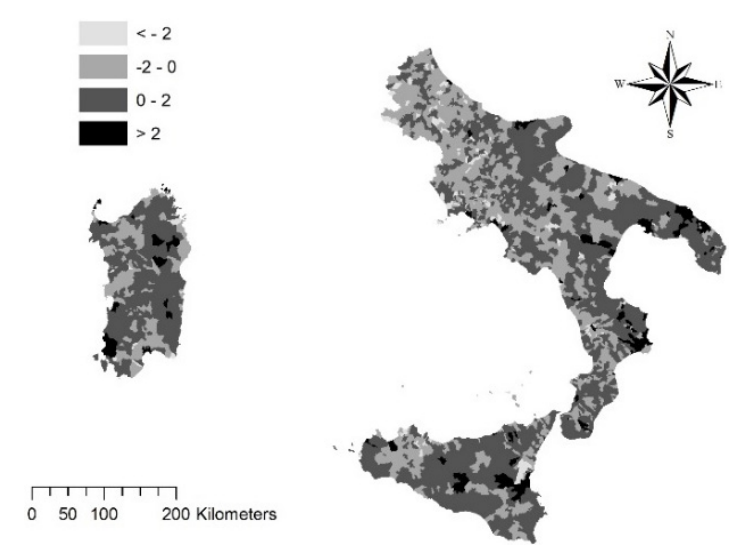

Axis 2
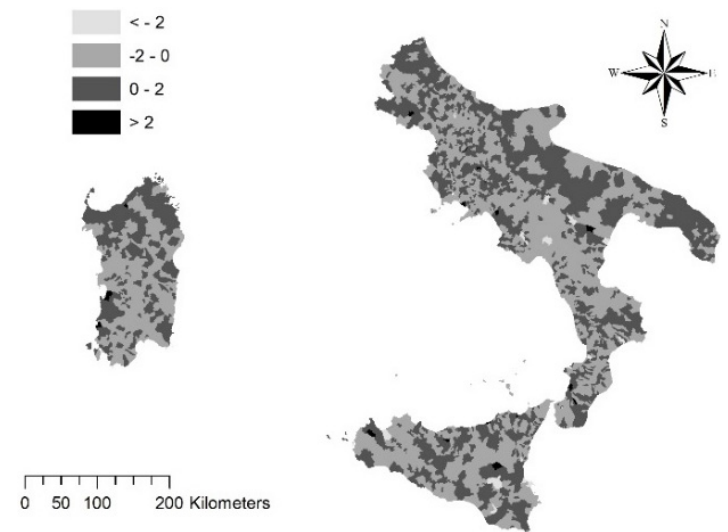

Axis 4

Figure 6. Spatial distribution of principal component scores in the municipalities of Southern Italy.

Component 2 assigned negative loadings to population growth in 1991-2001 and 2001-2011 and a positive loading for the decade 1871-1881. The spatial distribution of component scores was particularly heterogeneous: lowland and hilly rural municipalities, especially in Apulia, Calabria, and Sicily, received the highest positive scores. On the contrary, municipalities with low and negative scores were mainly located in the Apennine districts of Abruzzo and Campania. This component discriminates rural areas experiencing moderate growth in the initial decades of study (Apulia, Calabria, and Sicily) from rural districts undergoing intense depopulation in the most recent decades (Abruzzo and Campania).

Component 3 had a positive loading with population growth during 1881-1901 and a negative loading with population growth during 1931-1936. The spatial distribution of component scores shows a polarization in rural areas growing along the first decades of observation (Southern Sicily, part of Apulia, Northern Sardinia, and some districts of Calabria) and areas experiencing early depopulation in the inter-war period (Basilicata, internal Campania, Southern Sardinia). Component 4 identifies spatial patterns of population growth typical of 1921-1931 decade (the early stage of the Fascist era). This was a process of settlement expansion substantially independent from the previous ones, which involved Southern Italy in a particularly mixed way. The highest component scores were observed in flat and marshy rural areas where the Fascist regime had implemented extensive land reclamation programs, supporting population mobility from rural areas of Northern Italy (mainly from Veneto region).

\subsection{Non-Parametric Correlations}

A refined characterization of the principal components illustrated in the previous paragraph was derived from a non-parametric correlation analysis between component scores and selected attributes for each municipality (Table 4). 
Table 4. Non-parametric Spearman pair-wise correlations between component scores and contextual variables at the municipal scale in Southern Italy (only significant coefficients at $p<0.05$ were shown after Bonferroni's correction for multiple comparisons).

\begin{tabular}{|c|c|c|c|c|}
\hline Variable & PC 1 & PC 2 & PC 3 & PC 4 \\
\hline \multicolumn{5}{|l|}{ Territorial context } \\
\hline Proximity to sea coast & 0.36 & & & \\
\hline Elevation & -0.66 & & & \\
\hline \multicolumn{5}{|l|}{ Population density } \\
\hline 1861 & & -0.24 & & \\
\hline 1871 & & -0.22 & & \\
\hline 1911 & & & 0.23 & \\
\hline 1921 & 0.28 & & 0.24 & \\
\hline 1931 & 0.32 & & 0.21 & \\
\hline 1936 & 0.34 & & & \\
\hline 1951 & 0.41 & & & \\
\hline 1961 & 0.49 & & & \\
\hline 1971 & 0.57 & & & \\
\hline 1981 & 0.64 & & & \\
\hline 1991 & 0.69 & & & \\
\hline 2001 & 0.71 & & & \\
\hline 2011 & 0.74 & & & \\
\hline 2017 & 0.76 & & & \\
\hline
\end{tabular}

Results of non-parametric correlation analysis showed that coastal municipalities were associated with Component 1 . Component scores grew with population density since 1921, while decreasing with municipal elevation. Component 2 scores decreased with population density in the first two time points (1861 and 1871). Component 3 scores were positively correlated with population density at three times (1911, 1921, and 1931). Finally, Component 4 scores were not correlated with any territorial dimension.

\subsection{Cluster Analysis}

A non-hierarchical $k$-means clustering was run with the aim at classifying municipalities into homogeneous groups based on the most characteristic spatial patterns of population growth over time. Results of non-hierarchical clustering allow identification of local-scale dynamics reflecting long-term population trends. Three clusters formed the best partition of the sample, i.e., the number of clusters allowing for the most effective discrimination between elementary spatial units. A detailed profile of the three groups was illustrated in Table 5 using basic territorial descriptors that include population density and trends over time in population growth. Non-hierarchical clustering partitioned the sample of investigated municipalities quite homogeneously: more than one thousand municipalities were classified in both Cluster 1 and 3. By contrast, Cluster 2 was composed of nearly 350 municipalities.

Cluster 2 includes coastal municipalities with positive rates of population growth along the whole time period. The highest rates were observed between 1931-1936 and 1971-1981. Population density increased, on average, from 82 inhabitants $/ \mathrm{km}^{2}$ in 1861 to 457 inhabitants $/ \mathrm{km}^{2}$ in 2017. These municipalities include the main urban areas in Campania, Apulia, Sicily, and Sardinia (Figure 7). 
Table 5. Basic characteristics of Southern Italian municipalities by $k$-means cluster.

\begin{tabular}{|c|c|c|c|}
\hline Cluster & 2 & 1 & 3 \\
\hline Number of municipalities & 348 & 1121 & 1085 \\
\hline \multicolumn{4}{|l|}{ Territorial variables } \\
\hline Coastal municipalities (\%) & 52.0 & 29.4 & 11.2 \\
\hline Elevation $(\mathrm{m})$ & 115 & 304 & 565 \\
\hline Municipal area $\left(\mathrm{km}^{2}\right)$ & 48.9 & 54.7 & 41.1 \\
\hline \multicolumn{4}{|c|}{ Percent share of municipalities in the total number of municipalities by region } \\
\hline Campania & 32.5 & 24.6 & 14.8 \\
\hline Apulia & 18.7 & 14.1 & 3.1 \\
\hline Calabria & 8.0 & 15.3 & 19.3 \\
\hline Sicily & 14.7 & 14.6 & 16.1 \\
\hline Sardinia & 18.1 & 17.8 & 15.1 \\
\hline \multicolumn{4}{|c|}{ Annual population growth rate $(\%)$} \\
\hline $1861-1871$ & 0.89 & 0.61 & 0.45 \\
\hline $1871-1881$ & 1.15 & 0.89 & 0.48 \\
\hline 1881-1901 & 1.01 & 0.86 & 0.35 \\
\hline 1901-1911 & 1.11 & 0.73 & 0.25 \\
\hline 1911-1921 & 0.99 & 0.89 & 0.10 \\
\hline 1921-1931 & 1.34 & 0.04 & -0.37 \\
\hline 1931-1936 & 1.68 & 0.74 & 0.22 \\
\hline $1936-1951$ & 2.01 & 1.00 & 0.31 \\
\hline 1951-1961 & 1.85 & 0.54 & -1.10 \\
\hline 1961-1971 & 1.88 & -0.01 & -1.81 \\
\hline 1971-1981 & 1.72 & 0.42 & -0.88 \\
\hline 1981-1991 & 0.85 & 0.07 & -0.64 \\
\hline 1991-2001 & 0.31 & -0.08 & -0.59 \\
\hline 2001-2011 & 0.35 & 0.07 & -0.68 \\
\hline 2011-2017 & 0.41 & -0.01 & -1.77 \\
\hline \multicolumn{4}{|c|}{ Population density (inhabitants $/ \mathrm{km}^{2}$ ) } \\
\hline 1861 & 82 & 87 & 65 \\
\hline 1871 & 89 & 92 & 68 \\
\hline 1881 & 99 & 100 & 71 \\
\hline 1901 & 119 & 118 & 76 \\
\hline 1911 & 133 & 126 & 78 \\
\hline 1921 & 146 & 138 & 79 \\
\hline 1931 & 165 & 138 & 76 \\
\hline 1936 & 179 & 143 & 77 \\
\hline 1951 & 233 & 165 & 80 \\
\hline 1961 & 276 & 174 & 72 \\
\hline 1971 & 328 & 174 & 59 \\
\hline 1981 & 385 & 181 & 53 \\
\hline 1991 & 418 & 182 & 50 \\
\hline 2001 & 431 & 182 & 47 \\
\hline 2011 & 446 & 182 & 44 \\
\hline 2017 & 457 & 182 & 39 \\
\hline
\end{tabular}

Cluster 1 identifies coastal and inland municipalities in flat (or moderately hilly) areas, more frequently located in Campania, Apulia, and Sardinia. Average population growth rates for this cluster showed accelerated dynamics in the decades preceding World War II, and a substantial stability (or slight growth) in the following decades. Population density remained in line with the average values of municipalities belonging to Cluster 2 until 1901, increasing slowly up to 182 inhabitants $/ \mathrm{km}^{2}$ in 1991 and remaining stable in the following years. These municipalities represent heterogeneous locations with homogeneous demographic dynamics: (i) peri-urban areas, (ii) medium-small provincial head towns, (iii) flat and highly accessible rural areas, (iv) low-density coastal areas, and (v) hilly areas that have attracted industrial growth poles-often driven by state policies-especially in Abruzzo, Basilicata, Calabria, and Sardinia. Finally, Cluster 3 identifies mountain municipalities primarily located in Calabria. These municipalities experienced positive growth rates until 
1911-1921 and a substantial population decline afterwards, with progressively more intense negative rates, reaching the peak in the decade 1961-1971 and in the last period (2011-2017). On average, population density in the municipalities classified in cluster 3 stood at values not exceeding 80 inhabitants $/ \mathrm{km}^{2}$ (maximum density observed in 1951). The average density has halved in the last 60 years, evidencing processes of rural depopulation and progressive abandonment of mountain and marginal areas. All over Southern Italy, most of the inland municipalities have been classified in Cluster 3.

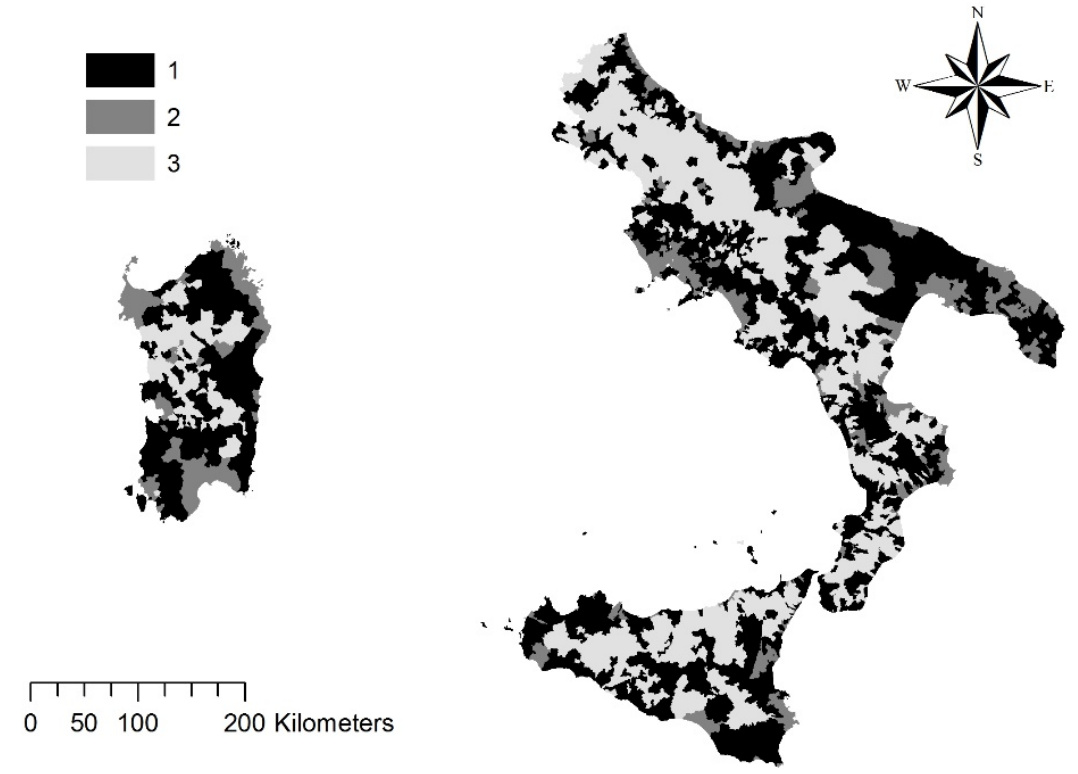

Figure 7. Classification of Southern Italian municipalities based on the results of a $k$-means clustering.

\subsection{Exploratory Regression Analysis}

Stepwise regressions were run separately for each decade of investigation with the aim at identifying the factors most associated with population growth in each municipality of Southern Italy (Table 6). The model's goodness-of-fit has been rather heterogeneous over time: Although all regressions were statistically significant, the model's goodness-of-fit (based on the values of the adjusted- $\mathrm{R}^{2}$ index) was rather modest until 1951. The most intense relationship between population growth and territorial variables was observed in periods of marked population increase (1951-1981) and accelerated demographic dynamics. In these periods, population density at the beginning of each observation period was the predictor most associated with population growth. This result confirms that population growth intensified in high-density (urban and peri-urban) districts since 1951. Completely different dynamics were observed in decades before World War II. The negative regression coefficients assigned to population density indicated how population increased in locations with lower population density. In other words, demographic expansion between 1861 and 1951 contributed to balance the spatial distribution of population in Southern Italy, while polarization in high- and low-density settlements increased with accelerated demographic dynamics in the aftermath of World War II. Elevation has represented an indirect constraint to population growth all over the study period. At the same time, the contribution of coastal areas to population growth was relatively modest until 1951, and more evident in some decades after World War II. All over the study period, the regions with the highest growth rates in the sample were Apulia and Campania. 


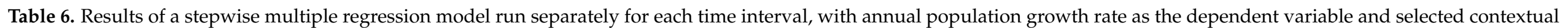
variables as predictors.

\begin{tabular}{|c|c|c|c|c|c|c|c|c|c|c|c|c|c|c|c|}
\hline Variable & $\begin{array}{l}1861- \\
1871\end{array}$ & $\begin{array}{l}1871- \\
1881\end{array}$ & $\begin{array}{l}1881- \\
1901\end{array}$ & $\begin{array}{l}1901- \\
1911\end{array}$ & $\begin{array}{l}1911- \\
1921\end{array}$ & $\begin{array}{l}1921- \\
1931\end{array}$ & $\begin{array}{l}1931- \\
1936\end{array}$ & $\begin{array}{l}1936- \\
1951\end{array}$ & $\begin{array}{l}1951- \\
1961\end{array}$ & $\begin{array}{l}1961- \\
1971\end{array}$ & $\begin{array}{l}1971- \\
1981\end{array}$ & $\begin{array}{l}1981- \\
1991\end{array}$ & $\begin{array}{c}1991- \\
2001\end{array}$ & $\begin{array}{l}2001- \\
2011\end{array}$ & $\begin{array}{l}2011- \\
2017\end{array}$ \\
\hline Proximity to the sea & & 0.06 & 0.06 & & & & & & 0.04 & 0.12 & 0.06 & & & 0.07 & 0.08 \\
\hline Apulia (dummy) & & 0.12 & 0.12 & 0.15 & 0.06 & & 0.08 & 0.09 & 0.07 & 0.05 & & & & -0.07 & -0.07 \\
\hline Sicily (dummy) & 0.11 & 0.26 & 0.17 & 0.09 & 0.13 & & & & 0.07 & & & & & -0.05 & -0.07 \\
\hline Calabria (dummy) & & & 0.08 & 0.16 & 0.13 & & & 0.13 & 0.07 & & -0.04 & & -0.11 & -0.13 & \\
\hline Campania (dummy) & & & & & 0.09 & & 0.19 & 0.16 & 0.17 & 0.09 & & 0.05 & & -0.06 & \\
\hline Sardinia (dummy) & -0.13 & -0.14 & & 0.14 & & -0.06 & & 0.09 & 0.18 & 0.16 & 0.11 & 0.04 & & & 0.10 \\
\hline Elevation & -0.12 & 0.26 & -0.22 & -0.20 & -0.24 & -0.20 & -0.29 & -0.28 & -0.38 & -0.21 & -0.19 & -0.18 & -0.20 & -0.16 & \\
\hline Municipal size & & & & & 0.15 & -0.08 & -0.06 & 0.13 & 0.12 & 0.17 & 0.08 & 0.06 & -0.11 & 0.04 & 0.31 \\
\hline Population density & -0.11 & -0.21 & -0.14 & -0.08 & -0.06 & -0.25 & -0.23 & -0.06 & 0.06 & 0.42 & 0.43 & 0.37 & 0.11 & 0.33 & 0.62 \\
\hline Adjusted $\mathrm{R}^{2}$ & 0.04 & 0.17 & 0.12 & 0.10 & 0.10 & 0.05 & 0.11 & 0.12 & 0.22 & 0.33 & 0.30 & 0.23 & 0.12 & 0.20 & 0.31 \\
\hline Durbin-Watson & 1.89 & 1.96 & 1.77 & 1.91 & 1.93 & 2.00 & 1.95 & 1.98 & 1.81 & 1.85 & 1.83 & 1.94 & 1.84 & 1.83 & 1.90 \\
\hline
\end{tabular}




\subsection{Spatial Distribution of Population Density as a Result of Long-Term Demographic Growth}

In parallel with a progressive growth of resident population, Table 7 illustrates trends over time in some metrics that assess the spatial distribution of population density in Southern Italy. In particular, the ratio between average and median density appears to be far from the unit value, declining over time since 1936. This decline indicates an increased asymmetry in the statistical distribution of population density. A similar trend was observed for the ratio between median and grand total density. The most recent values deviated significantly from one, indicating population concentration. A similar tendency has been observed for the relationship between (harmonic) average and grand total density. Variability metrics indicate a progressive increase of spatial heterogeneity in settlement density, with maximum values observed systematically at the end of the 'baby boom' (in 1971 or 1981 depending on the indicator). The relationship between the interquartile difference (75th-25th percentile) and absolute range of population density indicates a higher variability in recent times. Both kurtosis and skewness reach the peak in 1971.

A Principal Component Analysis run to investigate latent patterns of population concentration in Southern Italy highlights three distinct demographic stages (Figure 8). The biplot drawn on Component 1 (56.7\% of explained variance) and Component 2 (31.2\% of explained variance) indicates a homogeneous stage of growth between 1861 and 1951, associated with a high value of the median-to-arithmetic mean ratio in population density. A second stage, mostly oriented along Component 1 and associated with high values of both skewness and kurtosis in the statistical distribution of population density, was observed between 1951 and 1971. A third stage, oriented primarily along Component 2 and persistently associated with all the indexes of statistical variability, encompassed a relatively long time interval between 1971 and 2017.

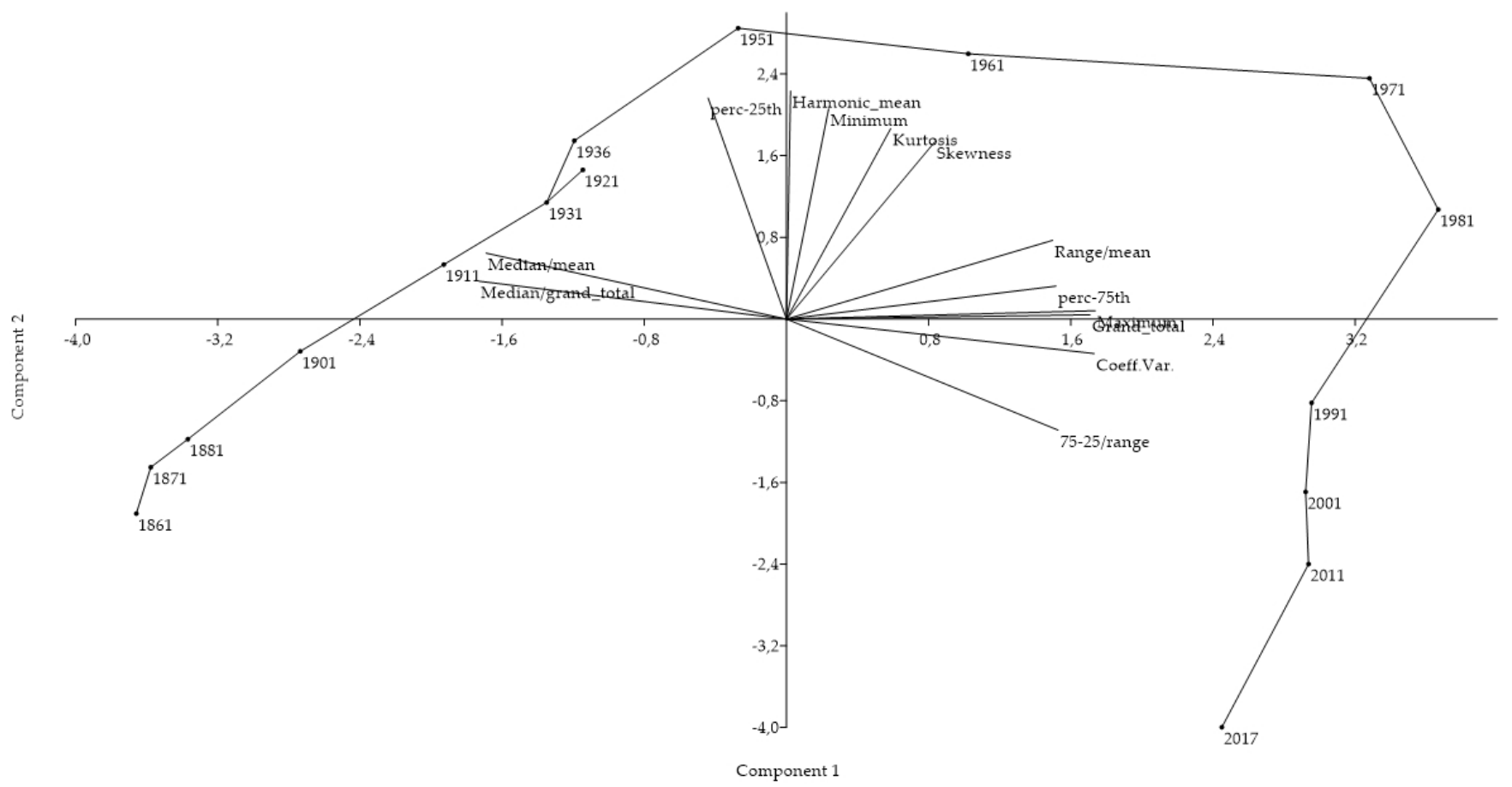

Figure 8. Biplot of a Principal Component Analysis run on metrics assessing spatial concentration of population in Southern Italian municipalities by year (a minimum spanning tree line connecting time points is also illustrated). 
Table 7. Descriptive statistics of the spatial distribution of population density (inhabitants $/ \mathrm{km}^{2}$ ) across Southern Italy municipalities, by year.

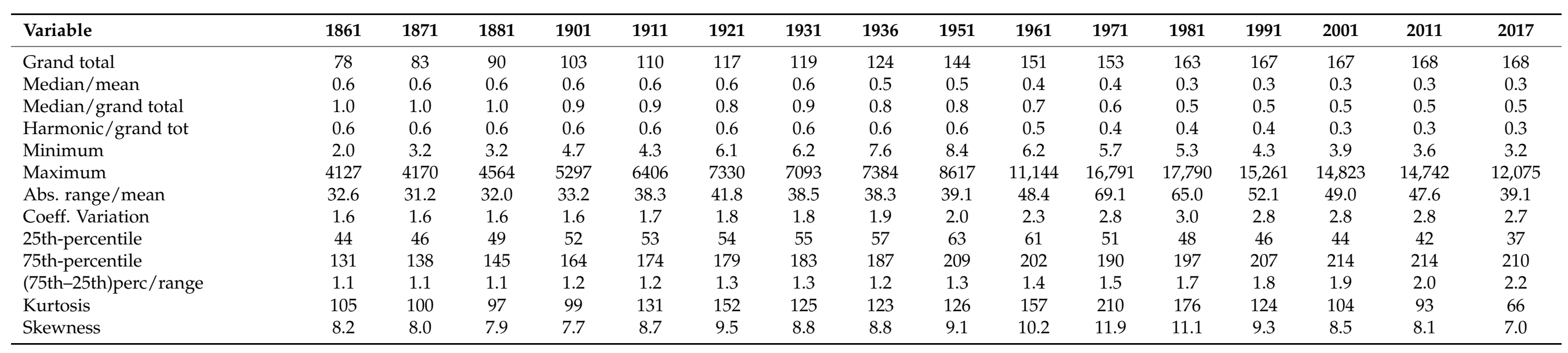




\section{Discussion}

Results of our study demonstrate the substantial distinctiveness of spatial population trends during the first and the second demographic transitions. While the first transition reflected spatially homogeneous population dynamics over both time and space, the second transition was more clearly associated with heterogeneous spatial patterns resulting from mixed, and mostly fragmented, individual behaviors as far as marriage, childbearing, and spatial mobility are concerned [16]. However, going beyond the linear and sequential interpretation of demographic dynamics delineated in earlier literature for European countries, the spatial outcomes of demographic transitions in Southern Italy were demonstrated to be particularly complex over time. Population dynamics were found articulated in four distinct stages: (i) a spatially homogeneous, moderate expansion between 1861 and 1911, (ii) a relatively slow population growth rebalancing a traditional divide in coastal and internal areas (1911-1951), (iii) accelerated population growth enlarging spatial divides in urban and rural districts (1951-1981), and (iv) population stability (or moderate decline) leading to an increased heterogeneity in demographic patterns since the early 1980s. Stages one to three outline a slow transition from models oriented toward high fertility and mortality to demographic patterns characterized by high fertility, low mortality, and accelerated population growth, in partial agreement with the predictions of the first demographic transition. Conversely, the fourth stage reflects lowest-low fertility and aging, being demographic outcomes more typical of the second transition.

Starting with the unification of Southern Italy within the Kingdom of Italy and ending before World War I, the first stage identified in our study was characterized by a spatially homogeneous growth of population, with higher rates in urban districts than in rural areas. The second stage encompassed the time interval between the two world wars, and featured accelerated population growth in inland flat areas, coastal districts, and urban settlements, and moderate depopulation of the Apennine mountainous region. The third stage extended over the first three decades after World War II, evidencing accelerated demographic dynamics typical of the 'baby boom' (1945-1975), intense migration to Northern Italy, and population aging in rural contexts. This stage also reflected a marked polarization of resident population along urban-rural gradients, with intense depopulation of marginal districts, and intense expansion of metropolitan agglomerations. The fourth stage encompassed the last four decades, from the lowest-low fertility of the 1980s to a moderate-while temporary-recovery in the 2000s [46]. During this period, depopulation continued uninterrupted in hyper-rural areas and was associated with a moderate growth of population in peri-urban districts and coastal lowlands [30].

Results of regression models indicate spread and long-term persistency of population growth as important factors influencing demographic dynamics and settlement characteristics in Southern Italy. In these regards, changes over time in spatial mobility patterns were mainly related to post-war socioeconomic transformations. While population increase in coastal and lowland areas was a dominant trend along the 20th century, even with intense emigration to Northern Italy and abroad, depopulation affected significantly mountain areas during the first demographic transition, contributing to the uneven marginalization of rural spaces [17]. Although less intense, depopulation was observed also during the second transition, in common with many other regions of Southern Europe, from Spain to Greece $[24,25,37]$. For instance, a particularly intense depopulation during the last two decades resulting in very low population densities at the local scale $\left(<10\right.$ inhabitants $\left./ \mathrm{km}^{2}\right)$ characterized most of internal municipalities of Central and Northern Spain and a large number of upland and mountainous municipalities in Central-Northern Greece and Peloponnese [29]. Taken together, these findings indicate that patterns of population concentration have been spatially persistent in Southern Italy at least until the early 1950s. Population dynamics in the subsequent decades consolidated the gap (i) between urban and rural municipalities within high-density and low-density (but economically dynamic and demographically expanding) districts, and (ii) between high- and low-density districts within both metropolitan and rural regions [25,37]. Although the backwash effects due 
to (relatively early and deep) industrialization of Northern Italy was hypothesized to be stronger than in other regions after World War II [22], our analysis confirms that population increase between 1951 and 1981 significantly impacted the spatial distribution of settlements in Southern Italy [46], with indirect implications for economic performances and the socio-demographic context at large [17]. The following decades, up to nowadays, were characterized by heterogeneous demographic processes that increased spatial variability without altering significantly the previous pattern of local development [15].

The empirical results of this study definitely point out the linkage between population growth and demographic dynamics in light of both economic cycles and metropolitan hierarchies. These findings reconnect the spatial outcomes of demographic transitions with long-term population trends and highlight distinctive stages intimately characterizing both the first and the second transition at a very local scale [4]. While some demographic phenomena are the result of socioeconomic transformations typical of a specific stage, other phenomena appear to be common to all the stages of population growth identified in this work, albeit with varying intensity [7]. For instance, rural depopulation remains a basic trend characterizing not only time periods with rapid population growth and intense internal migration, but also more recent times of low fertility, weak population growth, and intensified (short-range) spatial mobility [11]. In this case, population aging, internal migration towards Northern Italy, a resurgent emigration, and a poor attractiveness of international migrants-which reflects a substantial backwardness of inland areas-were recognized as the main factors contributing to rural depopulation during the second demographic transition in Southern Italy [32], and likely in other marginal socioeconomic contexts of Northern Mediterranean [29].

The empirical results of this study also indicate how the spatial distribution of resident population in Southern Italy reflects specific characteristics of past demographic transitions [12]. The most impacting phenomenon was likely the 'demographic boom' observed during the third phase identified in this study [47-50], in common with similar patterns observed at the European and national level (e.g., the so-called period of the 'Trente Glorieuses' (Thirty glorious years) in France encompassing 1945-1975 [6,48,49]). In such decades, Southern Italy population concentrated in urban areas, fueling the socioeconomic gap with rural districts and enlarging a broader-scale divide between regions, e.g., high fertility coastal districts of Campania vs. internal areas of Calabria and Sardinia [51-54]. Together with a stable (or weakly increasing) population in rural areas, metropolitan expansion after the 1980s affected this compact-dense settlement model less markedly $[40,55,56]$. Recent works have highlighted how the major urban agglomerations in Italy were progressively undergoing a new phase of suburban growth [31,57-59]. In such a context, the contribution of internal and international migration to population dynamics was found spatially differentiated in the last two decades [60-62]. While immigration drove population expansion in all agglomerations of Northern and Central Italy, urban growth in Southern Italy was more stagnant and more dependent on the natural population balance (births vs. deaths) $[26,60,61]$. In these regards, further studies should clarify the role of both rural-to-urban migration and urban mortality decline as (i) drivers of urbanization or (ii) factors triggering a metropolitan transition toward shrinkage $[7,21,27]$.

With the lowest-low fertility observed in Italy in the early 1990s, the demographic system of Southern Italy has reflected in the last three decades, more evidently than in the past, a polarized economic structure and marked social inequalities, in common with other Mediterranean regions, namely Southern Spain, rural Greece and, in part, Portugal [63-65]. Developmental policies specifically designed for all these contexts-being more or less heavily affected by 2007 recession-are strongly required to consider demographic issues as a basic aspect of post-crisis recovery, promoting endogenous growth and a more balanced structure of urban and rural areas [4]. To keep regions prosperous (promoting competitiveness) and to avoid inequality (maintaining cohesion), policy-makers should find ways to cope with these challenges through new fiscal and social policies [23], though measures impacting demographic and migratory trends may also be needed [66-68]. Taken together, 
these results—and especially population dynamics observed in the last decades-may encourage further research on additional, latent factors shaping population dynamics in Mediterranean countries, assuming demographic growth and urban-rural patterns as truly complex and intimately entropic issues [50,51]. This approach is intended as substantially far from traditional interpretations of population growth (and urban expansion) as additive and cumulated processes showing linear (or slightly non-linear) trends over time and space [4].

\section{Conclusions}

The evolution of metropolitan systems plays a crucial role in socioeconomic development of advanced economies $[35,40,44]$. Based on population change, urban transition in Italy was particularly accelerated over the three to four decades following World War II; urban-rural polarizations were in turn interpreted as a result of demographic dynamics typical of the first transition [69,70]. By contrast, the second transition was associated to increased spatial heterogeneity in population growth, impacting metropolitan expansion in a less predictable way in respect with past dynamics [71,72]. During both stages of growth, disadvantaged economic conditions, internal migrations towards Northern Italy, a structural job shortage, unstable socioeconomic conditions of internal districts, as well as a delayed infrastructural development enlarging the 'digital divide' with the rest of the country, were considered, at the same time, causes and consequences of a 'locked' demographic system. How to combine spatially balanced, socially cohesive and demographically resilient population growth in disadvantaged European areas is a major challenge for research in regional demography and sustainable development in the coming years.

Author Contributions: Conceptualization, G.Q. and R.S.; methodology, L.S.; validation, R.S.; formal analysis, R.S.; investigation, L.S.; resources, G.Q.; data curation, L.S.; writing-original draft preparation, R.S. and G.Q.; writing-review and editing, L.S.; visualization, R.S.; supervision, L.S.; project administration, G.Q. All authors have read and agreed to the published version of the manuscript.

Funding: This research received no external funding.

Institutional Review Board Statement: Not applicable.

Informed Consent Statement: Not applicable.

Data Availability Statement: Data is available at http:/ / www.istat.it (accessed on 1 June 2021).

Conflicts of Interest: The authors declare no conflict of interest.

\section{References}

1. Yi, Z.; Vaupel, J.W. The impact of urbanization and delayed childbearing on population growth and aging in China. Popul. Dev. Rev. 1989, 15, 425-445. [CrossRef]

2. Harte, J. Human population as a dynamic factor in environmental degradation. Popul. Environ. 2007, 28, 223-236. [CrossRef]

3. Potts, M. Population and environment in the twenty-first century. Popul. Environ. 2007, 28, 204-211. [CrossRef]

4. Zuindeau, B. Territorial equity and sustainable development. Environ. Values 2007, 16, 253-268. [CrossRef]

5. Rogers, A. Sources of urban population growth and urbanization, 1950-2000: A demographic accounting. Econ. Dev. Cult. Chang. 1982, 30, 483-506. [CrossRef]

6. Guérois, M.; Pumain, D. Urban Sprawl in France (1950-2000); Franco Angeli: Milan, Italy, 2002.

7. Lerch, M. The role of migration in the urban transition: A demonstration from Albania. Demography 2014, 51, 1527-1550. [CrossRef] [PubMed]

8. Sato, Y.; Yamamoto, K. Population concentration, urbanization, and demographic transition. J. Urban Econ. 2005, 58, 45-61. [CrossRef]

9. Greenwood, J.; Seshadri, A. The US demographic transition. Am. Econ. Rev. 2002, 92, 153-159. [CrossRef]

10. Galor, O. The demographic transition: Causes and consequences. Cliometrica 2012, 6, 1-28. [CrossRef]

11. Reher, D.S. Economic and social implications of the demographic transition. Popul. Dev. Rev. 2011, 37, 11-33. [CrossRef]

12. Lutz, W.; O'neill, B.C.; Scherbov, S. Europe's population at a turning point. Science 2003, 299, 1991-1992. [CrossRef] [PubMed]

13. Véron, J.; Horko, K.; Kneipp, R.; Rogers, G. The demography of South Asia from the 1950s to the 2000s. Population 2008, 63, 9-89. [CrossRef] 
14. Mazuy, M.; Barbieri, M.; D'albis, H.; Reeve, P. Recent demographic trends in France: The number of marriages continues to decrease. Population 2014, 69, 273-321.

15. Reher, D.S. The demographic transition revisited as a global process. Popul. Space Place 2004, 10, 19-41. [CrossRef]

16. Lesthaeghe, R. The second demographic transition: A concise overview of its development. Proc. Natl. Acad. Sci. USA 2014, 111, 18112-18115. [CrossRef] [PubMed]

17. Bonifazi, C.; Heins, F. Long-term trends of internal migration in Italy. Int. J. Popul. Geogr. 2000, 2, 111-131. [CrossRef]

18. Ogden, P.E.; Hall, R. The second demographic transition, new household forms and the urban population of France during the 1990s. Trans. Inst. Br. Geogr. 2004, 29, 88-105. [CrossRef]

19. Larramona, G. Out-migration of immigrants in Spain. Population 2013, 68, 213-235. [CrossRef]

20. Régnier-Loilier, A.; Vignoli, D.; Dutreuilh, C. Fertility intentions and obstacles to their realization in France and Italy. Population 2011, 66, 361-389. [CrossRef]

21. Bocquier, P.; Costa, R. Which transition comes first? Urban and demographic transitions in Belgium and Sweden. Demogr. Res. 2015, 33, 1297-1332. [CrossRef]

22. Vitali, A.; Billari, F.C. Changing determinants of low fertility and diffusion: A spatial analysis for Italy. Popul. Space Place 2017, 23, e1998. [CrossRef]

23. Rees, P.; Van der Gaag, N.; De Beer, J.; Heins, F. European regional populations: Current trends, future pathways, and policy options. Eur. J. Popul. 2012, 28, 385-416. [CrossRef] [PubMed]

24. Kabisch, N.; Haase, D. Diversifying European agglomerations: Evidence of urban population trends for the 21st century. Popul. Space Place 2011, 17, 236-253. [CrossRef]

25. López-Gay, A. Population growth and re-urbanization in Spanish inner cities: The role of internal migration and residential mobility. Rev. Quetelet 2014, 1, 67-92. [CrossRef]

26. Strozza, S.; Benassi, F.; Ferrara, R.; Gallo, G. Recent demographic trends in the major Italian urban agglomerations: The role of foreigners. Spat. Demogr. 2016, 4, 39-70. [CrossRef]

27. Haase, A.; Kabisch, S.; Steinführer, A.; Bouzarovski, S.; Hall, R.; Ogden, P. Emergent spaces of reurbanisation: Exploring the demographic dimension of inner-city residential change in a European setting. Popul. Space Place 2010, 16, 443-463. [CrossRef]

28. Carlucci, M.; Grigoriadis, E.; Rontos, K.; Salvati, L. Revisiting a hegemonic concept: Long-term 'Mediterranean urbanization' in between city re-polarization and metropolitan decline. Appl. Spat. Anal. Policy 2017, 10, 347-362. [CrossRef]

29. Carella, M.; Pace, R. Some migration dynamics specific to southern Europe: South-north and east-west axis. Int. Migr. 2001, 39, 63-99. [CrossRef]

30. Bonifazi, C.; Heins, F. Testing the differential urbanisation model for Italy. Tijdschr. Econ. Soc. Geogr. 2003, 94, 23-37. [CrossRef]

31. Zambon, I.; Serra, P.; Sauri, D.; Carlucci, M.; Salvati, L. Beyond the 'Mediterranean city': Socioeconomic disparities and urban sprawl in three Southern European cities. Geogr. Ann. Ser. B Hum. Geogr. 2017, 99, 319-337. [CrossRef]

32. Bonifazi, C.; Heins, F. Internal migration patterns in Italy: Continuity and change before and during the Great Recession. Riv. Ital. Econ. Demogr. Stat. 2017, 71, 2-10.

33. Morelli, V.G.; Rontos, K.; Salvati, L. Between suburbanisation and re-urbanisation: Revisiting the urban life cycle in a Mediterranean compact city. Urban Res. Pract. 2014, 7, 74-88. [CrossRef]

34. De Rosa, S.; Salvati, L. Beyond a 'side street story'? Naples from spontaneous centrality to entropic polycentricism, towards a 'crisis city'. Cities 2016, 51, 74-83. [CrossRef]

35. Zaninetti, J.M. Urban sprawl in France. A regional typology of urbanization trends and its demographic and economic background. Bull. Geogr. Soc. Econ. Ser. 2006, 5, 5-20.

36. Colantoni, A.; Mavrakis, A.; Sorgi, T.; Salvati, L. Towards a 'polycentric' landscape? Reconnecting fragments into an integrated network of coastal forests in Rome. Rend. Lincei 2015, 26, 615-624. [CrossRef]

37. Bayona-I-Carrasco, J.; Gil-Alonso, F.; Pujadas-I-Rúbies, I. Suburbanisation versus recentralisation: Changes in the effect of international migration inflows on the largest Spanish metropolitan areas (2000-2010). Quetelet J. 2014, 2, 93-118. [CrossRef]

38. Kotzamanis, B.; Baltas, P.; Kostaki, A. The Trend of Period Fertility in Greece and Its Changes During the Current Economic Recession. Popul. Rev. 2017, 56, 2. [CrossRef]

39. Caltabiano, M.; Dreassi, E.; Rocco, E.; Vignoli, D. A subregional analysis of family change: The spatial diffusion of one-parent families across Italian municipalities, 1991-2011. Popul. Space Place 2019, 25, e2237. [CrossRef] [PubMed]

40. Bonavero, P.; Dematteis, G.; Sforzi, F. The Italian Urban System. Towards European Integration; Ashgate: Aldershot, UK, 1999.

41. ISTAT. Popolazione Residente nei Comuni, Censimenti dal 1861 al 1991; Istituto Nazionale di Statistica: Rome, Italy, 1994.

42. ISTAT. Atlante Statistico dei Comuni; Istituto Nazionale di Statistica: Rome, Italy, 2006.

43. Rontos, K.; Grigoriadis, E.; Sateriano, A.; Syrmali, M.; Vavouras, I.; Salvati, L. Lost in protest, found in segregation: Divided cities in the light of the 2015 "Oxı" referendum in Greece. City Cult. Soc. 2016, 7, 139-148. [CrossRef]

44. Cuadrado-Ciuraneta, S.; Durà-Guimerà, A.; Salvati, L. Not only tourism: Unravelling suburbanization, second-home expansion and "rural" sprawl in Catalonia, Spain. Urban Geogr. 2017, 38, 66-89. [CrossRef]

45. Duvernoy, I.; Zambon, I.; Sateriano, A.; Salvati, L. Pictures from the other side of the fringe: Urban growth and peri-urban agriculture in a post-industrial city (Toulouse, France). J. Rural Stud. 2018, 57, 25-35. [CrossRef]

46. Caltabiano, M.; Castiglioni, M.; Rosina, A. Lowest-low fertility: Signs of a recovery in Italy? Demogr. Res. 2009, 21, 681-718. [CrossRef] 
47. Pérez, M.D.; Livi-Bacci, M. Fertility in Italy and Spain: The lowest in the world. Fam. Plan. Perspect. 1992, 24, 162-171. [CrossRef]

48. Prioux, F.; Mandelbaum, J. Recent demographic developments in France: Fertility at a more than 30-year high. Population 2007, 62, 417-456. [CrossRef]

49. Pawin, R. Retour sur les «Trente Glorieuses» et la périodisation du second XXe siècle. Rev. D’Histoire Mod. Contemp. 2013, 1, 155-175. [CrossRef]

50. Pison, G. France and Germany: A history of criss-crossing demographic curves. Popul. Soc. 2012, 487, 1.

51. Di Feliciantonio, C.; Salvati, L. 'Southern' Alternatives of Urban Diffusion: Investigating Settlement Characteristics and SocioEconomic Patterns in Three Mediterranean Regions. Tijdschr. Econ. Soc. Geogr. 2015, 106, 453-470. [CrossRef]

52. Carlucci, M.; Chelli, F.M.; Salvati, L. Toward a new cycle: Short-term population dynamics, gentrification, and re-urbanization of Milan (Italy). Sustainability 2018, 10, 3014. [CrossRef]

53. Delfanti, L.; Colantoni, A.; Recanatesi, F.; Bencardino, M.; Sateriano, A.; Zambon, I.; Salvati, L. Solar plants, environmental degradation and local socioeconomic contexts: A case study in a Mediterranean country. Environ. Impact Assess. Rev. 2016, 61, 88-93. [CrossRef]

54. Di Feliciantonio, C.; Salvati, L.; Sarantakou, E.; Rontos, K. Class diversification, economic growth and urban sprawl: Evidences from a pre-crisis European city. Qual. Quant. 2018, 52, 1501-1522. [CrossRef]

55. Ferreira, V.; Samora-Arvela, A.; Panagopoulos, T. Soil erosion vulnerability under scenarios of climate land-use changes after the development of a large reservoir in a semi-arid area. J. Environ. Plan. Manag. 2016, 59, 1238-1256. [CrossRef]

56. Karamesouti, M.; Detsis, V.; Kounalaki, A.; Vasiliou, P.; Salvati, L.; Kosmas, C. Land-use and land degradation processes affecting soil resources: Evidence from a traditional Mediterranean cropland (Greece). Catena 2015, 132, 45-55. [CrossRef]

57. Kelly, C.; Ferrara, A.; Wilson, G.A.; Ripullone, F.; Nolè, A.; Harmer, N.; Salvati, L. Community resilience and land degradation in forest and shrubland socio-ecological systems: Evidence from Gorgoglione, Basilicata, Italy. Land Use Policy 2015, 46, 11-20. [CrossRef]

58. Kosmas, C.; Karamesouti, M.; Kounalaki, K.; Detsis, V.; Vassiliou, P.; Salvati, L. Land degradation and long-term changes in agro-pastoral systems: An empirical analysis of ecological resilience in Asteroussia-Crete (Greece). Catena 2016, 147, 196-204. [CrossRef]

59. Naranjo Gómez, J.M.; Lousada, S.; Velarde, J.G.; Castanho, R.A.; Loures, L. Land-use changes in the Canary archipelago using the CORINE data: A retrospective analysis. Land 2020, 9, 232. [CrossRef]

60. Panagopoulos, T.; Duque, J.A.G.; Dan, M.B. Urban planning with respect to environmental quality and human well-being. Environ. Pollut. 2016, 208, 137-144. [CrossRef] [PubMed]

61. Pili, S.; Grigoriadis, E.; Carlucci, M.; Clemente, M.; Salvati, L. Towards sustainable growth? A multi-criteria assessment of (changing) urban forms. Ecol. Indic. 2017, 76, 71-80. [CrossRef]

62. Recanatesi, F.; Clemente, M.; Grigoriadis, E.; Ranalli, F.; Zitti, M.; Salvati, L. A fifty-year sustainability assessment of Italian agro-forest districts. Sustainability 2016, 8, 32. [CrossRef]

63. Salvati, L. The Dark Side of the Crisis: Disparities in per Capita income (2000-2012) and the Urban-Rural Gradient in Greece. Tijdsch. Econ. Soc. Geogr. 2016, 107, 628-641. [CrossRef]

64. Salvati, L.; Ciommi, M.T.; Serra, P.; Chelli, F.M. Exploring the spatial structure of housing prices under economic expansion and stagnation: The role of socio-demographic factors in metropolitan Rome, Italy. Land Use Policy 2019, 81, 143-152. [CrossRef]

65. Salvati, L.; Sateriano, A.; Grigoriadis, E. Crisis and the city: Profiling urban growth under economic expansion and stagnation. Lett. Spat. Resour. Sci. 2016, 9, 329-342. [CrossRef]

66. Salvati, L.; Serra, P. Estimating rapidity of change in complex urban systems: A multidimensional, local-scale approach. Geogr. Anal. 2016, 48, 132-156. [CrossRef]

67. Salvati, L.; Zambon, I.; Chelli, F.M.; Serra, P. Do spatial patterns of urbanization and land consumption reflect different socioeconomic contexts in Europe? Sci. Total Environ. 2018, 625, 722-730. [CrossRef]

68. Serra, P.; Vera, A.; Tulla, A.F.; Salvati, L. Beyond urban-rural dichotomy: Exploring socioeconomic and land-use processes of change in Spain (1991-2011). Appl. Geogr. 2014, 55, 71-81. [CrossRef]

69. Smiraglia, D.; Ceccarelli, T.; Bajocco, S.; Salvati, L.; Perini, L. Linking trajectories of land change, land degradation processes and ecosystem services. Environ. Res. 2016, 147, 590-600. [CrossRef] [PubMed]

70. Vaz, E.; Shaker, R.R.; Cusimano, M.D.; Loures, L.; Arsanjani, J.J. Does land use and landscape contribute to self-harm? A sustainability cities framework. Data 2020, 5, 9. [CrossRef]

71. Zambon, I.; Benedetti, A.; Ferrara, C.; Salvati, L. Soil matters? A multivariate analysis of socioeconomic constraints to urban expansion in Mediterranean Europe. Ecol. Econ. 2018, 146, 173-183. [CrossRef]

72. Zare, M.; Panagopoulos, T.; Loures, L. Simulating the impacts of future land use change on soil erosion in the Kasilian watershed, Iran. Land Use Policy 2017, 67, 558-572. [CrossRef] 